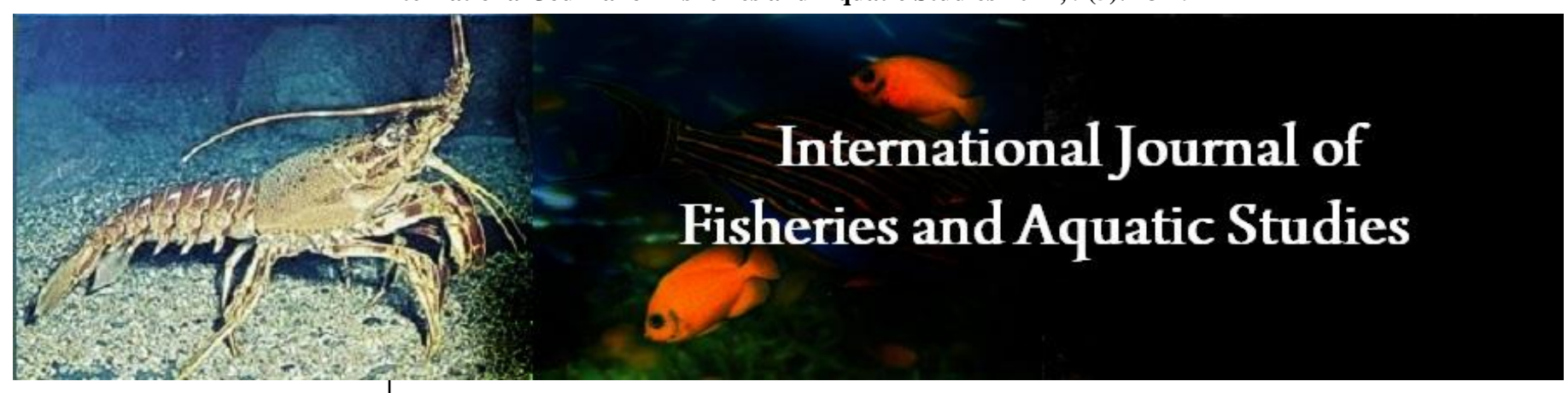

E-ISSN: 2347-5129

P-ISSN: 2394-0506

(ICV-Poland) Impact Value: 5.62

(GIF) Impact Factor: 0.549

IJFAS 2021; 9(5): 23-29

(C) 2021 IJFAS

www.fisheriesjournal.com

Received: 12-07-2021

Accepted: 19-08-2021

Kumar Sahayaraju

Kadalamma-Centre for Ocean

Sustainability Education,

Research and Development

Thiruvananthapuram, Kerala

India

Johnson Jament

Kadalamma-Centre for Ocean

Sustainability Education,

Research and Development

Thiruvananthapuram, Kerala, India
Corresponding Author:

Kumar Sahayaraju

Kadalamma-Centre for Ocean

Sustainability Education,

Research and Development

Thiruvanathapuram, Kerala,

India

\section{Loss of marine fish stock in south west India: Examining the causes from the perspective of indigenous fishermen}

\author{
Kumar Sahayaraju and Johnson Jament
}

DOI: https://doi.org/10.22271/fish.2021.v9.i5a.2559

\begin{abstract}
The study area is a potent biodiversity spot and the indigenous coastal livelihood heavily depends upon the region's fish resources in the south-west coast of India. They are spread around 35 indigenous fishing villages and having a reef enriched coast of about 80 kilometres. Data were collected through focus group discussions and key informant interviews. All of the discussants were indigenous community members and citizen scientists in the region. The collected indigenous data were validated using the available literature and reports. The result showed the rich marine biodiversity knowledge persists among indigenous fishers, specifically regarding the importance of seabed ecosystems. These are considered as natural assets with respect to the ecosystem services provided by them and the respective livelihood practices possible for the indigenous fishing community. This also indicates a very strong traditional livelihood practice which conserves biodiversity of the ocean and their sustainable use for generations. However, the results also indicated with visual and followed literature evidences, currently, these biodiversity were at a risk of getting extinct and/or endangered. Consequently, this also led to the loss of livelihood in the study areas. Coupled with them, there are various natural and anthropogenic pressures such as Climate Change, Overfishing, Pollution and destructive developmental practices in the area.
\end{abstract}

Keywords: Seabed ecosystem, indigenous knowledge, marine biodiversity, endangered species, destructive practices

\section{Introduction}

The ocean is the largest and most important biological resource on earth. Interestingly, about eighty percent of the ocean's biodiversity is still unknown (National Oceanographic and Atmospheric Administration, 2018). The world has so far discovered about ten million species of marine life, including a variety of fish, plants and microorganisms. About 2,000 new marine lives are discovered around the world each year. So many creatures are emerging from the sea. More than half of the Earth's primary food producers and more than half of the Earth's oxygen are produced from this marine biodiversity. Therefore, the ocean deserves more consideration and protection than any other ecosystem (World Ocean Congress, 2017). In the coast of Kerala, more than 15042 species of marine biodiversity have been identified, including sponges, cnidarians, mollusks, arthropods, echinoderms, fish, turtles, sea snakes, sea mammals and seabirds (Keralathile Kadaljeevikal, 2012).

All of these findings are from studies conducted only in selected locations, so there is still much more to discover. The seas from Kanyakumari to Kollam are one of the most biologically rich seas (Vinod et al. 2014) in India. The marine habitats in these areas are mainly coastal, deep sea, and estuaries. Coastal shores are home to a wide variety of crab species and intertidal creatures that live both on land and along the coast. The coast is home to plankton, an important component of the marine ecosystem. These planktons are responsible for the production of oxygen. At the same time, they are the first producers of the earth's food chain. The coastal ecosystems are one of the richest and most diverse habitats in the ocean, which is a place to small fish and creatures that feed on them. In the deep sea there are large fishes but small in number, mammals and sea creatures. Estuaries are places where rivers naturally join the sea. The estuaries and estuaries adjacent to the sea are livelihood area to a wide variety of seabirds such as pirates, earthworms and seagulls. The main marine ecosystems of the southeastern Arabian Sea, including Kanyakumari, are the coastal reefs. These reefs are the main livelihood source of traditional fishermen, which they referred to as paaru. 
These ecosystems were discovered by fishermen themselves and have been fishing for generations. Although such ridges are mainly rock formations, sandy bottom ridges, floor slopes and sloping ridges are the only features of the sea floor in this region. It offers habitat to a large number of mussels, small and large fish, and plants and organisms that live in the sea bed (Panippilla \& Jament, 2016) ${ }^{[11]}$. In the light of the knowledge of traditional fishermen, rare species of sea creatures, including seagulls, have been found in these reefs for the first time in India (Friends of Marine Life, 2019). Hook and line fishing is a method of fishing that distinguishes the traditional fishermen of the Thiruvananthapuram from others. The baits are used to catch fish from the seabed. Hook and line fishing is the most environmentally friendly fishing method that does not harm the seabed. During the Monsoon season, boat fishing and net fishing are the main activities. Along with this, there are various fishing methods, such as mussel fishing and nest lobster fishing. It should be noted that none of these traditional fishing methods cause great harm to the sea. Yet, indigenous fishermen say that there has been a sharp decline in fish availability, species over the past few years. Fishermen also justify that many fish have already disappeared. This paper examines and studies the knowledge and experience gathered from traditional fishermen on the challenges facing marine biodiversity and its causes. The traditional fishermen here are more knowledgeable about the marine biodiversity and the seabed habitat than the mainstream scientific community. That is why many oceanographic studies in Kerala have relied on traditional fishermen to collect samples from the sea. The indigenous fishermen of Thiruvannathapuram have made a large contribution in the preparation of marine biodiversity register of India, which is for the first time in the nation. Moreover, it is the traditional fishermen who have seen and known the sea creatures that are now extinct, hidden and currently undocumented in the sea. Given the fact that there are very few scientific studies in these areas, this paper validates the knowledge of traditional fishermen using the available literatures. The main learning objectives include to collect information on different types of marine habitats and their characteristics along the coast of the Thiruvananthapuram district, to document the details of extinct marine species from the traditional knowledge of indigenous fishermen, factually check for loss of biological resources and learn the reasons behind the loss of biodiversity from the experiences of traditional fishermen.

\section{Materials and Methods}

The main study is focused on the traditional fishing villages from Pozhiyoor to Mampally in the district of Thiruvananthapuram in Kerala, South India. Over one and a half million people and about 54023 traditional fishermen residing in these coastal villages; which are the highest in the state of Kerala. Collected information on the loss of fish stocks and its causes from fishermen from Pozhiyoor to Mampally through the "Kadalkoodam" Ocean Literacy Program conducted by the Coastal Students Cultural Forum, a community of coastal students in the district. From Kadalkkoodam, identified the fishermen who are expert in indigenous and local knowledge (Chelalees). The Chelalikoottam- ocus Group discussions were organized in Pozhiyoor, Karumkulam, Vizhinjam, Poonthura and Anjengo villages and collected information on the reasons of marine biodiversity loss along the coast of south-west India. Twenty selected fishermen and ten key informants based in villages from Anjengo to Poovar were interviewed in person. Data on seabed were collected from Friends of Marine Life (FML), a citizen science research center for marine biodiversity which works in collaboration with traditional fishermen. The ideas were compiled by reading and analyzing studies related to this subject and field. The collected data and indigenous knowledge were validated using the available literature.

\section{Results and Discussion}

The marine ecosystem is more diverse than the biodiversity in the land. Fishermen refer to the seabed ecosystem of fish and marine life as paaru (reefs). The reefs on the coast of Thiruvananthapuram are very different than other regions of the state. The South-West Arabian Sea contains reservoirs of reefs which are identified by the indigenous fishermen .Most of the reefs are rocky and some of them are sandy. It also includes Semi Platform reefs, platform reefs and rocky reefs. Sunken areas also have become a marine ecosystem which is called shipwreck reefs. Along with the colony of coral species and muscles, they have a richness of diversity in fishes, which has made these reefs the main occupational space for indigenous fishermen for generations. Each reef is named by the indigenous fishermen according to the fish habituating there and its geomorphological reefs.

Panthaakkallu, Perumakkallu, Polakkettu, Poottala Mada are some of the examples. Each traditional fishing village in Thiruvannathapuram having at least one natural reefs in its coast. These reefs and its fish availability are playing a significant role in the regional economy of the village. For example, Karumkulam, a fishing village in the study area is getting its most of the finance from the catch of file-fishes of the Balistidae family, locally known as klathi. Klathi (odonus niger) is uniquely residing only in the reefs of Karumkulam coast. Also the indigenous names of the fishes are also indicating its morphological and biological features. For example, Kallappi (Kallu means rock) habituating only in the midst of reefs. Kilimeen (Kili means bird) having different colors on its body. Kalumeen always shows its skill to escape from the fishermen.

Kozhippara paru, Madan Paru, Panavilakode Kallu, Parayan Kallu, Neruv Kallu, Kulathukal Paru, Charupara Kallu, Avananku, Anakallu, Nediya Kallu, Kurangu Kallu, Perungallu, Valayidichan Kallu and Azhimala Paru are the rocky reefs from Mullur to Valiyathura in Thiruvananthapuram. The reefs from sunken ship wrecks are also found in Anjengo and Muttom. Fishermen have a wide range of knowledge about these reefs, especially for those who go to the bottom of the sea and collect mussels, shells and lobster. They are commonly known as "Kuzhiyalikal". The most famous of them are residing in the Mullur-Kovalam coast in Thiruvananthapuram district and the Inayam village in Kanyakumari district. Along with mussels, they also collect sea weeds, sea urchins and sea cucumber.

From the experience of the fishermen, the availability of various species of fish in these marine habitats and in the sea in general has been declining for the last several years. They also say that although the catch of the species such as Notoli (Anchovy), Ayala (Mackerel), Chala (Sardine), Chilaw (baraccuda) and Vala (Ribbon fish) is still available, their availability has been reduced. The number of fishes caught from the rocky reefs has also decreased significantly. Traditional fishermen tabulated that there are few fishes which are completely extinct from the region. Paduvatt 
Navara (Mullets), Prachi, Mana, Kaluthed, Chennavara (Red Mullets), Tolan, Soles, Numb Fish, Torpido Ray and Valayodu, which were found in the rocky reefs of Thiruvananthapuram district, have already disappeared from the sea. Nevertheless, these fishes are not included in the red lists released by the International Union for Nature Conservation and other conservation agencies. Kerala fisheries statistics also underpin the traditional fishermen concerns raised about the fish loss.

According to the Government of Kerala's figures for 2019, there is a huge increase in the availability of fish from the sea even though this increase is due to the large catch of small fish. At the same time, it is noted that these fish are declining sharply when it comes to counting the number of fish caught from the reefs. These declining fish species are exactly the species that have been marked extinct by traditional fishermen. At the same time, the fishermen say, there has been a significant decline in the type, size and number of fish being caught in each season. The monsoon species such as prawns, squid, ribbon fish have not been caught since the last two monsoon season. Fishermen point out that these are the reasons for the decline in fish availability;

\section{Increase in the number of (mechanized) fishing vessels}

Traditional fishermen say that the increase in the number of fishing vessels in Kerala during the last 20 years has led to more unsustainable large scale fishing and that over time, it has reduced the availability of fish. As part of the IndoNorwegian project implemented in the 1950s, the fisheries sector in Kerala have also been increasingly mechanized until the traditional fishing vessels and methods slowly faded away. Traditional fishing vessels such as barges and boats, as well as the sustainable fishing methods they used, such as baiting, net fishing and other ocean-friendly fishing methods, have given way to mechanized vessels and their competitive fishing methods. This has led to large-scale catch of fish from the sea. Numerous studies haveshown that excessive and unstable fishing has significantly reduced marine fish stocks. We can see the history of Thiruvananthapuram district defending there as well. The fishermen of this district continued their traditional fishing even after Kerala as a whole adopted fishing methods like trawling. Statistics show that they have reduced their use of traditional fishing vessels such as canoes and boats, yet never used trolling boats for their occupation. Trolling is a method of fishing that destructs the entire bottom of the sea. This will upset the balance of the marine habitat, the seabed and the rocks. The fishermen of Thiruvananthapuram district did not adopt this method of fishing as they were fishing in the sea beds and these beds play a major role in the marine ecosystem.

\section{Unrestricted and Unstable Fishing Methods}

Fishermen say the trawling boats introduced as part of the Indo-Norwegian project have proven the most dangerous fishing method ever used. In the early days, these were outside the Thiruvananthapuram district. Although the fishing range for these boats is beyond 12 nautical miles, traditional fishermen say that trawling boats from other districts come here and destroy the reefs, even up to three kilometers from the shore. In addition, trawling is banned in Kerala during the months of June and July. But there is no ban on trawling in Tamil Nadu during these months. As it is a district close to Tamil Nadu, large boats from other parts of the state also come to the Thiruvananthapuram district for large-scale fishing. All this is leading to a drastic reduction in the fishery resources of the region, especially the traditional reefs. At the same time, fishing with Ring Seines and Ghost Nets, which are harmful to marine habitats, is destroying the marine ecosystem. There were a minor trend of fishing using these nets in Thiruvananthapuram district too, but the indigenous fishermen prevented the large-scale use of these; particularly in Anjengo regions.

\section{Warming of Ocean}

Climate change is affecting marine habitats both globally and locally. The warming of the oceans is causing the extinction of marine life, which lacks the biological structure to withstand the heat. As the oceans absorb gases that cause global warming, the oceans become more acidic, leading to the loss of marine biodiversity. This leads to the destruction of marine habitats and the liquefaction of coral reefs. A 2017 study by the Thiruvananthapuram-based Friends of Marine Life found that such coral reefs were beginning to be destroyed in the seas off the Inayam region of Kanyakumari. Climate change is generally said not to affect the deep sea. However, deep-sea biodiversity is largely adapted to stable temperature conditions. Therefore, when the temperature changes due to climate change, the deep sea biodiversity will no longer be able to adapt.

"Kuluthi" is a term used by tradition fishermen to indicate the coldness of the sea. However, they say the weather has not been this cold for some years. Cold and rainfall play a major role in the growth of marine biodiversity. However, the availability of this cold and rainy season has been greatly reduced in recent years. The monsoon season is crucial for fishermen and the sea. Rain, wind and currents during this time carry more organic matter to the sea. This is also the time of the fish breeding. The currents in the ocean at monsoon contribute to the phenomenon of "Karaneerilakkam", which is important for the reproduction and availability of marine biodiversity. Still, the fishermen said there was no strong monsoon or Karaneerilakkam after the cyclone Ockhi. Warming and the resulting hurricanes in the Arabian sea are destroying marine habitats. Fishermen share the experience of more storms in the Arabian Sea than in the past. They also say that fish stocks have dropped significantly after the tsunami and hurricane. Studies have shown that this is the case. The Arabian Sea has experienced an average of 2 hurricanes a year over the past decade. In 2019 alone, there were 5 storms. It also affects the ocean floor. Due to this, the availability of fish is declining due to strong heat wave (Murakami \& Vechi, 2017) ${ }^{[6]}$.

\section{Plastic and Pollution}

Cletus, a native of Puthiyathura who has been at sea for forty years, says, "Now when I go to sea, I catch more plastic and debris than fish in the nets. There is no fish on the seabed at all". The Friends of Marine Life's research on the seabed in Kanyakumari also provides information on the plastic waste and pollution of the sea in this region. Along with the domestic waste, the government and the people treating the sea as a dumping ground for tourism, cities and industries. The amount of this waste is increasing every year as natural waste is cut and sewage channels are extended into the sea. Waste, including plastic, enters the sea and feeds on it, leading to mass extermination of marine life. The level of oxygen in the sea is reduced due to the release of organic matter and toxins into the sea through sewage and the sea 
areas become dead zones where fish cannot live. In addition, it causes the mass growth of algae, which are harmful to nature. The effluents released by the Travancore Titanium Factory in the Veli-Vettucaud region of Trivandrum districts polluting the ocean for generations. This factory has been dumping about 120 tons of Sulphuric acid along with Ferrous Sulphate, Titanus Sulphate, Manganeese Sulphate in every day for years. This causes the reduction of oxygen in this region and it leads to the depletion of marine biodiversity; a study conducted by coastal ocean monitoring and prediction in 2014 reveals.

\section{Development Killing Marine Biodiversity}

The marine biodiversity in the Mullur-Vizhinjam-Kovalam area play an important role in the fisheries of the district. In a scientific paper published in the Geo-Marine Science, researchers A.J. Biju Kumar and R. Ravinesh talk in detail about the marine biodiversity in the region. Vizhinjam is an intertidal region. The study recorded 147 species from the region. They include 32 species of seaweeds, 11 species of sponges, six types of celenterates, and 2 types of bryozoans. 31 species of sea snails (molluscs), seven sea worms (annelids), two types of snails found in the mud (sipunculids), 12 species of prawn-like creatures (amphipods) known as isopods, amphibods, crab-like herb (crab) There are 12 other types of brachyuran crabs and 12 species of alpheid shrimps. The study also states that when the excavation of the Mullur sea for the construction of the Vizhinjam port was started, all the species of oysters in the area became extinct. Also it leads the destruction of Seven sea worms (annelids), two sipunculids found in the mud, Isopods, 12 amphipods with amphibian-like body structure known as amphipods, hermit crab and 12 other types of crabs), 12 species of alpheid shrimps. However, it is a fact that the Vizhinjam International Multipurpose Deep Sea Port Construction Project kills this marine warehouse in Thiruvananthapuram, which is known for its biodiversity.

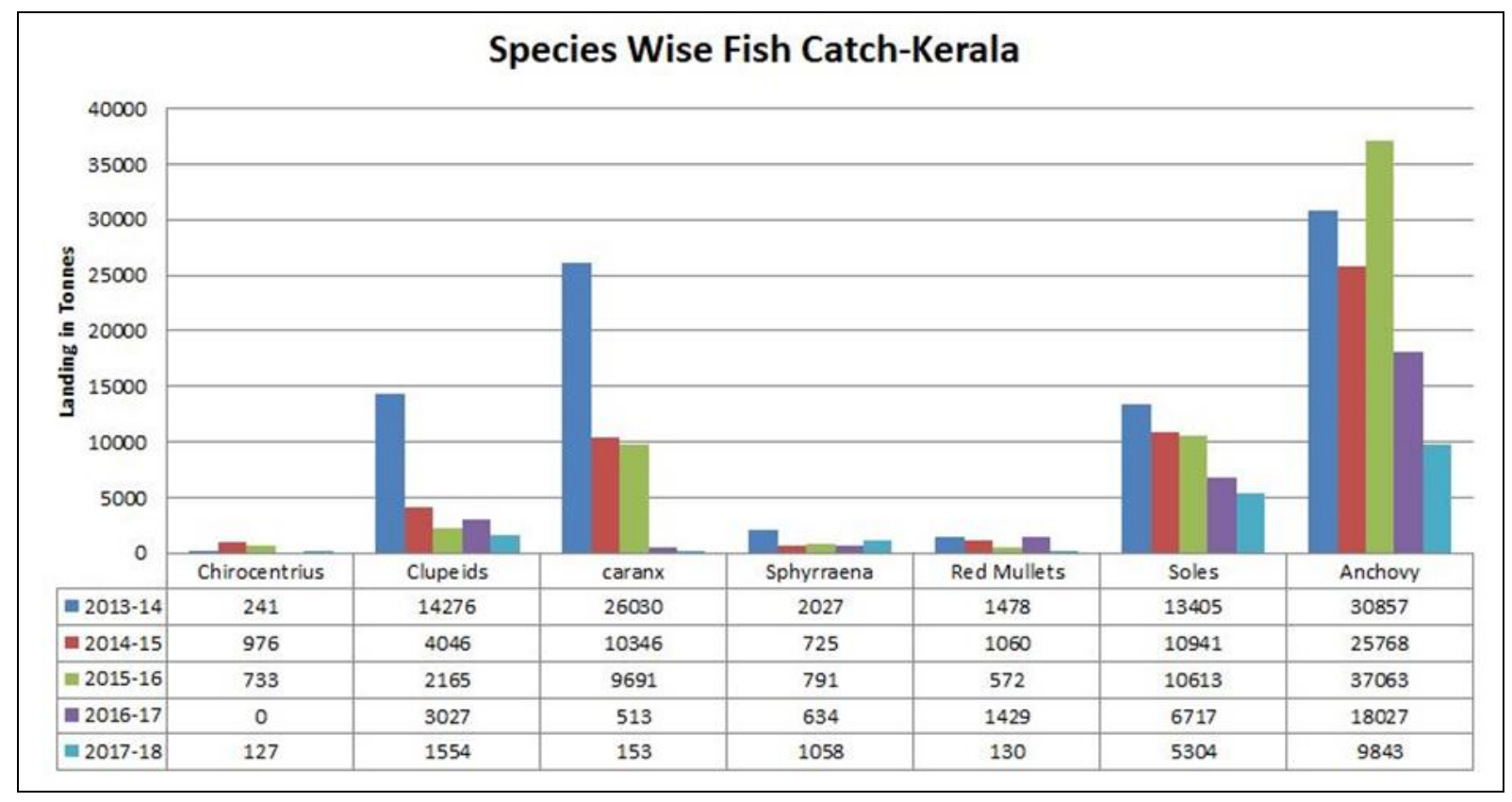

Fig 1: Species Wise Fish Catch in Kerala (2013-18) from Fisheries Handbook, Govt of Kerala

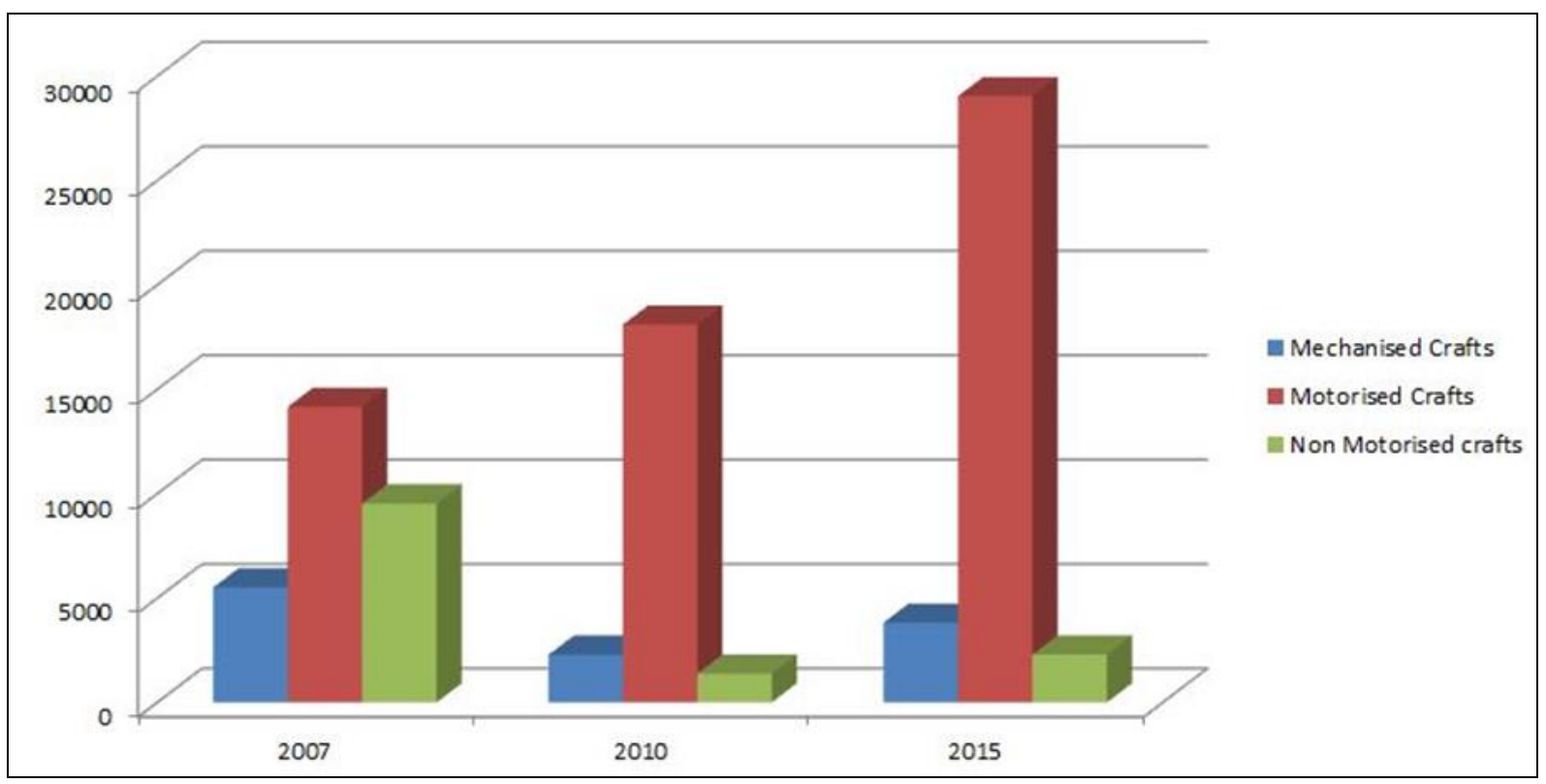

Fig 2: Number of Fishing Vessels in Kerala (2007-15) from Marine Fisheries Statistics, CMFRI 


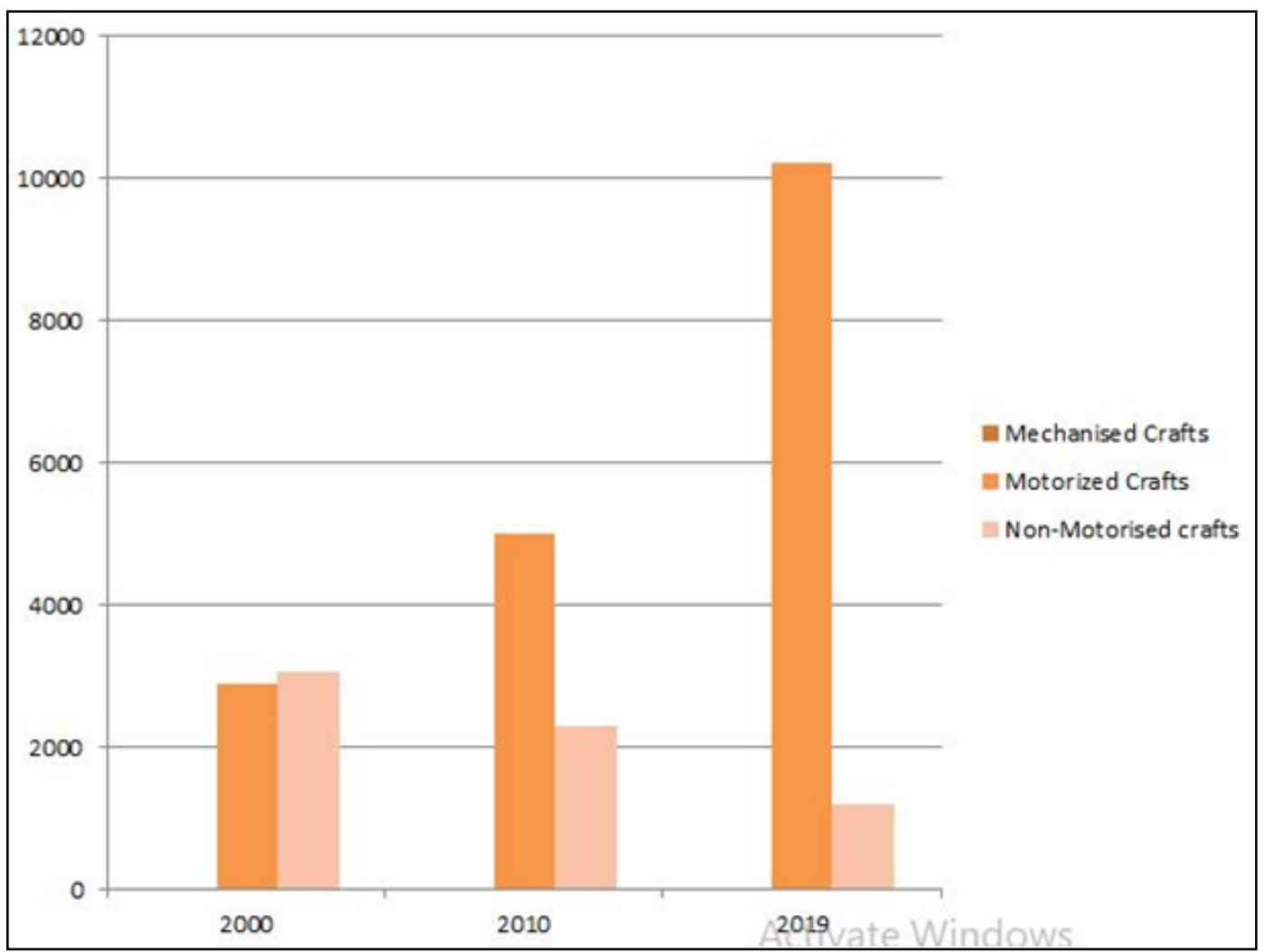

Fig 3: Number of Fishing Vessels in Thiruvananthapuram (2000-19) from Marine Fisheries Statistics, CMFRI
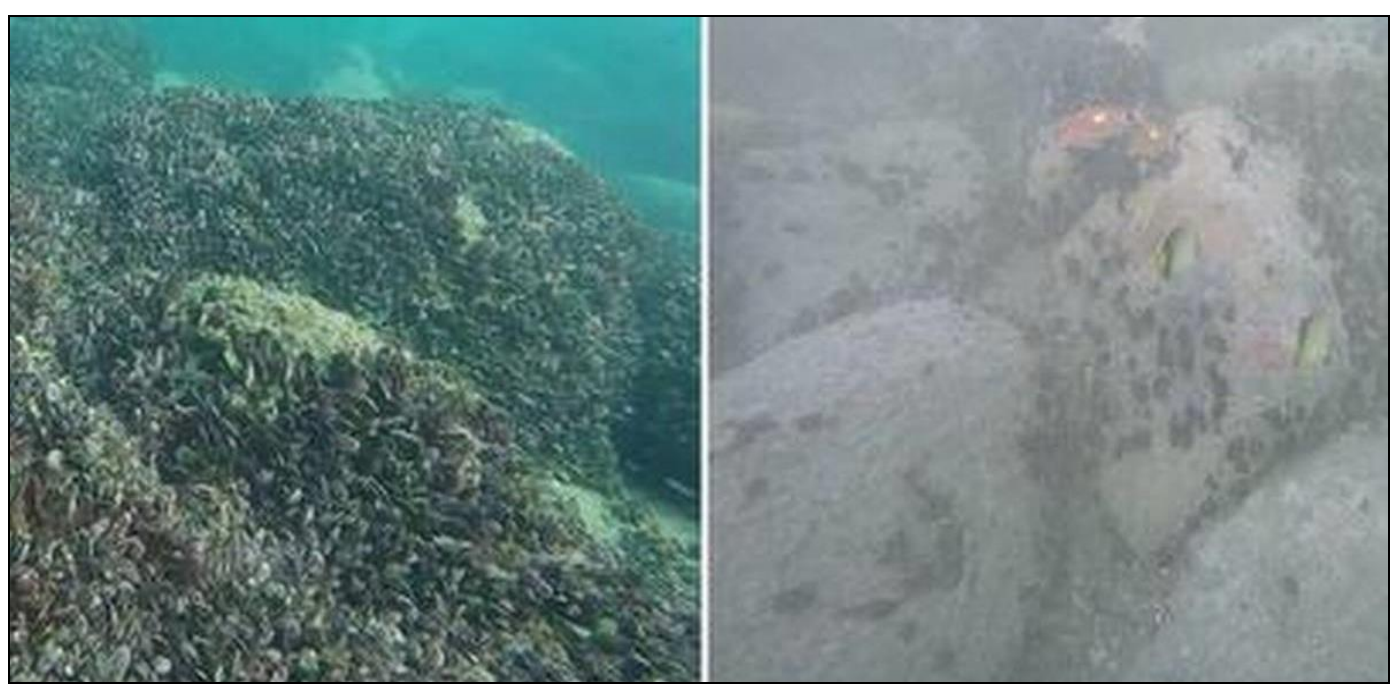

Fig 4: Muscle Colonies in Kovalam: before and after Cyclone Ockhi Courtesy: Friends of Marine Life (FML)

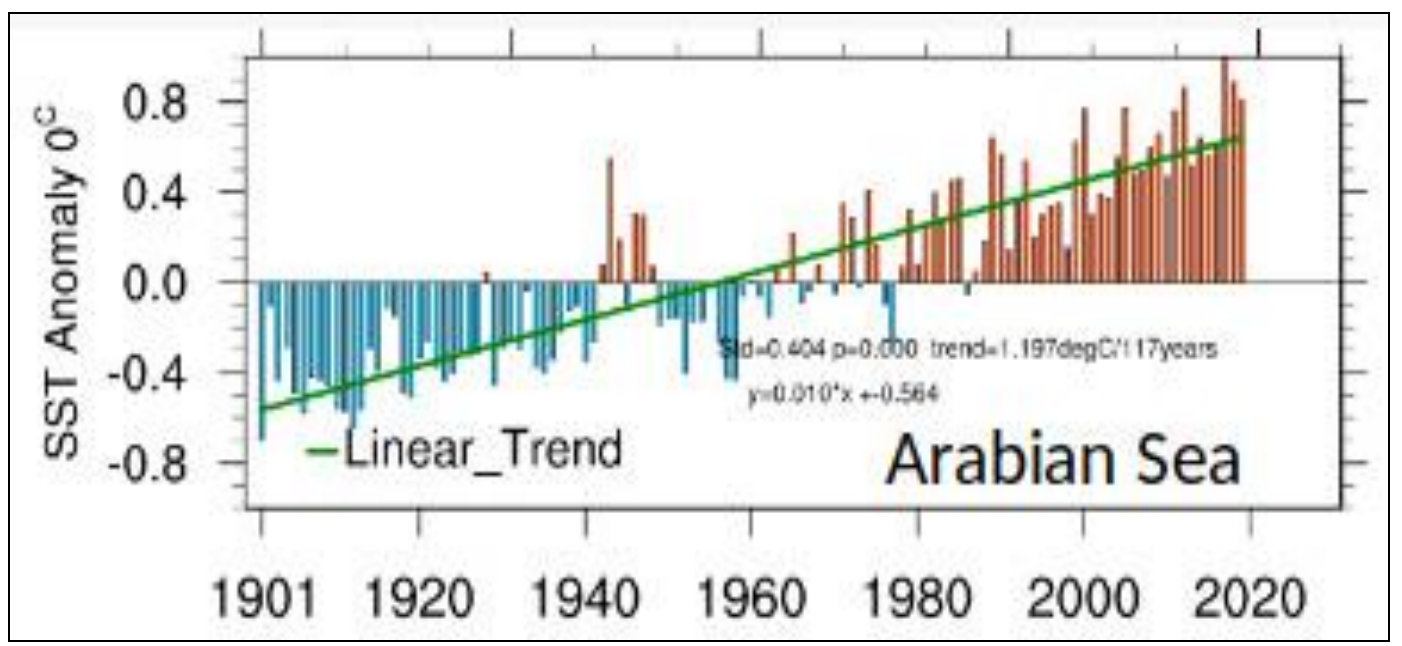

Fig 5: Temperature variations in Arabian Sea Courtesy: CUSAT, 2019 


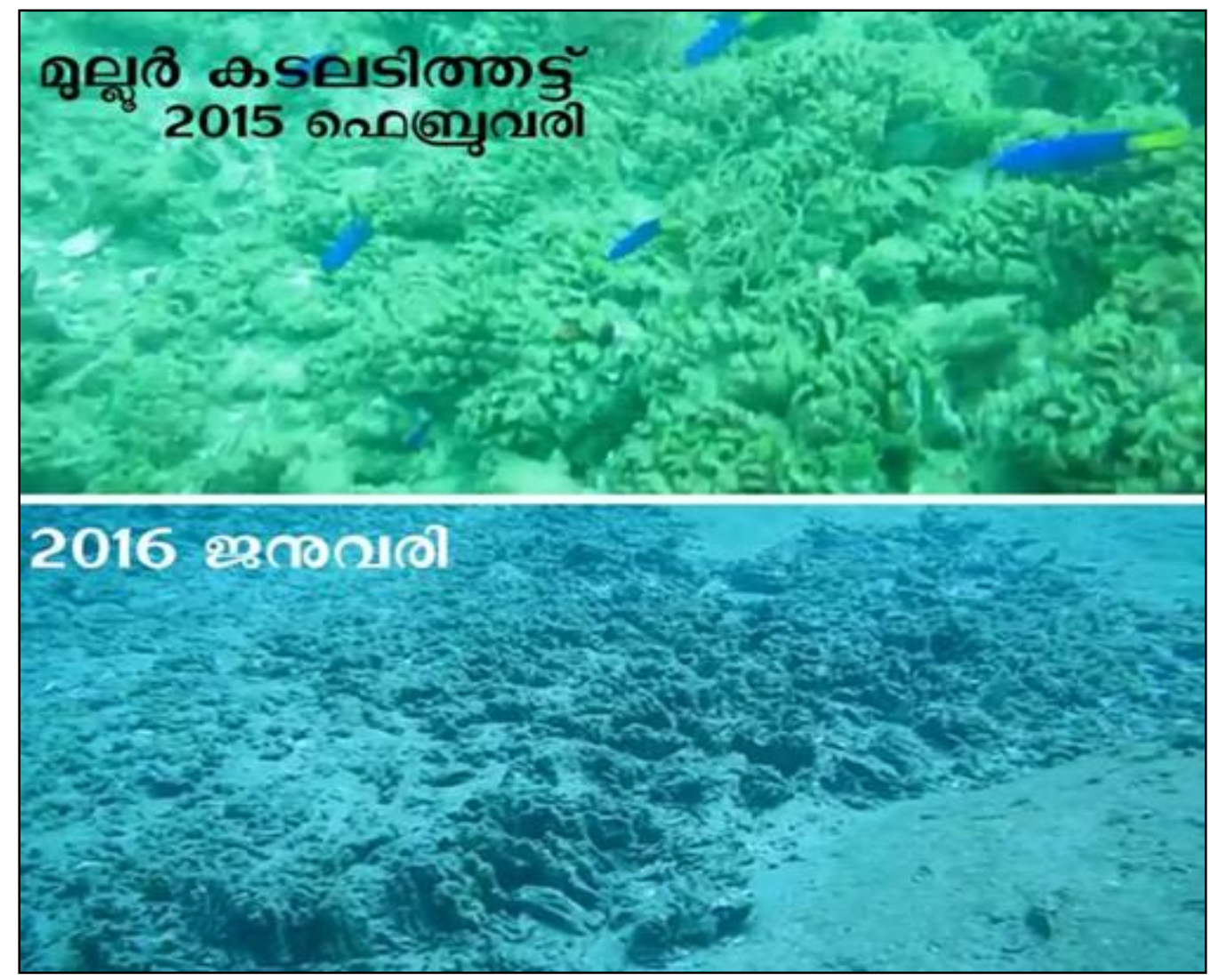

Fig 6: Colonies of Tubeworm in Kovalam. Before and after dredging for Vizhinjam Port Courtesy: Friends of Marine Life, 2016

Table 1: Rocky reefs in Thiruvanathapuram identified by indigenous Fishermen

\begin{tabular}{|c|c|c|c|}
\hline Name of the reefs & $\begin{array}{l}\text { Located } \\
\text { Village }\end{array}$ & $\begin{array}{l}\text { Depth (In Maaru- Traditional } \\
\text { Measurement of Fishermen ) }\end{array}$ & Fishes available \\
\hline Polikkallu & Pozhiyoor & 18.5 & Squid \\
\hline Koruvakkettu & Pozhiyoor & & \\
\hline Pendakkettu Eranakkadu & Pozhiyoor & 30 & Groupers \\
\hline Chappapparu Ullikkallu & Poovar & & Scads Groupers \\
\hline Tholambaaru Neduvakkettu & Poovar & 35 & Mullets Perciformes \\
\hline Mathekkettu Poottalakkettu & Kallumukku & 7.8 & Flatfishes Sea bass Tuna Cardinal Fishes Squid \\
\hline Kinathadikkettu & Kallumukku & -- & \\
\hline Othakkallu Cheelanthikkallu Ocham & Karumkulam & & Mackerel Grouper Squid \\
\hline Vannarapparu Maipparu & Karumkulam & 28 & Odonus niger \\
\hline Polakkallu (Ponapparu) & Karumkulam & 19.5 & Parrot Fish Moron Fishes Snappers Wrasses Squid \\
\hline Oolikkettu & Karumkulam & 29 & Baraccuds \\
\hline Cheriyavila & Kochuthura & 20 & Cabia Dolphin Fishes \\
\hline Panthakkallu & Kochuthura & -- & Lobsters \\
\hline Paarameen Kallu & Puthiyathura & -- & Lactarilidae \\
\hline Neduvakkettu & Puthiyathura & -- & Scats \\
\hline Molapparu Puthankettu & Pulluvila & -- & Soles Flat fishes \\
\hline Perumakkallu & Adimalathura & -- & Lobsters Groupers Muscles \\
\hline Methankettu & Vizhinjam & 22 & Silver Sillagus \\
\hline Thalakkallu & Kovalam & & Pomphet \\
\hline Molavarakkallu Neravu & Poonthura & 32 & -- \\
\hline Oolapparu Kelantha Evu & Poonthura & -- & -- \\
\hline Kappalpparu & Poonthura & 36 & -- \\
\hline
\end{tabular}

\section{Conclusion}

In Kerala, the sea in Thiruvananthapuram district is famous for its unique and rich biodiversity. These parrots and their wildlife play an important role in the availability of fish and the balance of nature. Traditional fishermen have adopted fishing practices that protect these habitats. However, due to various global and regional factors, the fisheries of the region are facing difficulties. More than a dozen species of fish have already become extinct. Many species of mussels, coral reefs and their species are on the verge of extinction. A large decrease in the availability of each fish species is demonstrated. This is due to excessive and unsustainable fishing practices, climate change, pollution and unscientific development practices. The sea and its creatures need to be protected, or even more so, than the marine environment and living things. Further study and strict precautionary measures are urgently needed. Accurate studies and conservation measures (Marine Biodiversity register and auditing, marineprotected areas, marine species for marine species, marine spatial planning) are needed to determine the importance of 
biodiversity here, their biodiversity and the reasons for its loss.

\section{References}

1. Baiju PT, Prabhakaran MP, Benno Pereira FG, Jayaprakas V. Rocky Reef associated fish diversity of South Kerala Coast, India. Journal of Aquatic Biology \& Fisheries 2016;4:31-44.

2. Bijukumar M. Keralatheerathe Kadal jeevikal , Kerala State Biodiversity Board 2012.

3. Fisheries Hand Book (2017, 2019), Government of Kerala

4. Jisha Elisabeth. Keralathe Kathirikkunnath Mahadurantham, Madhyamam 2019.

5. Marine Fisheries Statistics (2010, 2015), CMFRI

6. Murakami H, Vecchi GA, Underwood S. Increasing frequency of extremely severe cyclonic storms over the Arabian Sea. Nature Clim Change 2017;7:885-889.

7. National Biodiversity Authority, India. People's Biodiversity Register. NBA: Government of India 2013.

8. Outcomes of the UN SDG 14 Conference. Intergovernmental Oceanographic Commission 2017.

9. Panipilla R. Eyes on their Fingertips. Chennai: International Collectives in Support of Fisher workers (ICSF) 2015.

10. Panipilla R, Jament J. Case Study: Mukkuva Community in South India: socio-religious history and biocultural diversity. Knowledges of Nature 102017.

11. Panippilla R, Kumar B, Jament J, Benedict A. Preparation of Marine Biodiversity Register and the Documentation of Traditional Knowledge and Indigenous Practices of Fishermen in the Trivandrum Coast, Kerala, India. IPBES-JBF Sub-regional Dialogue Workshop Report on Indigenous and Local Knowledge (ILK) for South and West Asia sub-region: pp. 29-32, Tokyo Office, Institute for Global Environmental Strategies (IGES) 2016.

12. Ravinesh R, Bijukumar A. Comparison of intertidal biodiversity associated with natural rocky shore and sea wall:a case study from the Kerala coast, India. Indian J Geo-Mar Sci 2013;42:223-235

13. S A, Krishnakumar EK, Vijaykumar P, et al. Changing Characteristics of Droughts over Kerala, India: InterAnnual Variability and Trend. Asia-Pacific J Atmos Sci 2019;55:1-17.

14. Yedudas L. Social Identity Revealed through Dialect - A study based on the bilingual area of Karumkulam Panchayath, Unpublished PhD thesis, Thiruvananthapuram: University of Kerala 2020.

15. Yesudas L, Jement J. Marine Biodiversity \& Cultural Diversity: The Coastal Communities of Trivandrum, Kerala, India. Langscape 2015;4(1):39-43. 